\title{
Application of Fuzzy Set Theory to Quantitative Analysis of Correctness of the Mathematical Model Based on the ADI Method during Solidification
}

\author{
Xiaofeng Niu, ${ }^{1}$ Guanqian Wang, ${ }^{1}$ Wei Liang, ${ }^{1}$ Hua Hou, ${ }^{2}$ \\ Hongxia Wang, ${ }^{1}$ and Jinshan Zhang ${ }^{1}$ \\ ${ }^{1}$ College of Materials Science and Engineering, Taiyuan University of Technology, Taiyuan 030024, China \\ ${ }^{2}$ College of Materials Science and Engineering, North University of China, Taiyuan 030051, China
}

Correspondence should be addressed to Wei Liang; liangweityut001@126.com

Received 20 July 2013; Revised 21 October 2013; Accepted 24 October 2013

Academic Editor: SunQun Cao

Copyright (C) 2013 Xiaofeng Niu et al. This is an open access article distributed under the Creative Commons Attribution License, which permits unrestricted use, distribution, and reproduction in any medium, provided the original work is properly cited.

The explicit finite difference (EFD) method is used to calculate the casting temperature field during the solidification process. Because of its limited time step, the computational efficiency of the EFD method is lower than that of the alternating direction implicit (ADI) method. A model based on the equivalent specific heat method and the ADI method that improves computational efficiency is established. The error of temperature field simulation comes from model simplification, the acceptable hypotheses and calculation errors caused by different time steps, and the different mesh numbers that are involved in the process of numerical simulation. This paper quantitatively analyzes the degree of similarity between simulated and experimental results by the hamming distance (HD). For a thick-walled position, the time step influences the simulation results of the temperature field and the number of casting meshes has little influence on the simulation results of temperature field. For a thin-walled position, the time step has minimal influence on the simulation results of the temperature field and the number of casting meshes has a larger influence on the simulation results of temperature field.

\section{Introduction}

The 3D heat transfer equation of the temperature field during the solidification process is as follows [1-3]:

$$
\begin{gathered}
\rho c_{p} \frac{\partial T}{\partial t}=\lambda\left(\frac{\partial^{2} T}{\partial x^{2}}+\frac{\partial^{2} T}{\partial y^{2}}+\frac{\partial^{2} T}{\partial z^{2}}\right)+\dot{Q}, \\
\dot{Q}=\rho Q \frac{\partial f_{s}}{\partial t},
\end{gathered}
$$

where $T$ is the temperature, $t$ is the time, $\rho$ is the average density of the liquid phase and the solid phase, $c_{p}$ is the specific heat, $\lambda$ is the convectional parameter, $\dot{Q}$ is the inner heat source, and $Q$ is the latent heat, $f_{s}$ is the solid phase fraction.

The energy conservation equation is usually solved by the EFD method, and computational efficiency is lower due to its limited time step [4-6].
The critical time step $\Delta t$ in the EFD method can be taken as follows [6-8]:

$$
\Delta t \leq \frac{\rho c_{p}}{\left[2 \cdot \lambda \cdot\left(1 / \Delta x^{2}+1 / \Delta y^{2}+1 / \Delta z^{2}\right)\right]},
$$

where $\Delta x, \Delta y$, and $\Delta z$ are the mesh sizes in the $X, Y$, and $Z$ directions, respectively.

In this study, the equivalent specific heat method is adopted to describe the latent heat and the high-order ADI method that is fourth order in space and second order in time. This high-order mathematical model is based on the equivalent specific heat method, and the high-order ADI method is more accurate than the EFD method [7-12].

The error of temperature field simulation comes from model simplification, the acceptable hypotheses and calculation errors of the different time steps, and the different mesh numbers involved in the process of numerical simulation. 
TABLE 1: Truncation errors.

\begin{tabular}{lr}
\hline Method & Truncation errors \\
\hline This new high-order mathematical model & Fourth order in space and second order in time \\
The EFD method & Second order in space and first order in time \\
\hline
\end{tabular}

The degree of similarity between the simulation and the experimental results is quantitatively analyzed using the hamming distance [13-15].

\section{Mathematical Model}

The energy conservation equation can be given as the following:

$$
\begin{gathered}
\rho c_{p} \frac{\partial T}{\partial t}=\lambda\left(\frac{\partial^{2} T}{\partial x^{2}}+\frac{\partial^{2} T}{\partial y^{2}}+\frac{\partial^{2} T}{\partial z^{2}}\right)+\rho Q \frac{\partial f_{s}}{\partial t}, \\
f_{s}=\frac{\left(T_{L}-T\right)}{\left(T_{L}-T_{S}\right)},
\end{gathered}
$$

where $T_{L}$ is the temperature of the liquid phase and $T_{S}$ is the temperature of the solid phase. With the equivalent specific heat method [8]:

$$
\begin{gathered}
\rho c_{p}^{\prime} \frac{\partial T}{\partial t}=\lambda\left(\frac{\partial^{2} T}{\partial x^{2}}+\frac{\partial^{2} T}{\partial y^{2}}+\frac{\partial^{2} T}{\partial z^{2}}\right), \\
c_{p}^{\prime}= \begin{cases}c_{p} & T \geq T_{L} \\
c_{p}-Q \frac{\partial f_{s}}{\partial t} & T_{L}>T \geq T_{S} \\
c_{p} & T<T_{S} .\end{cases}
\end{gathered}
$$

The discretization equations of this high-order mathematical model based on the equivalent specific heat method and the high-order ADI method can be given as the following:

$$
\begin{aligned}
{[1+} & {\left.\left[\frac{\Delta x^{2}}{12}-\frac{k \Delta t}{2}\right] \delta_{x}^{2}\right] T_{i j k}^{* *} } \\
= & {\left[1+\left[\frac{\Delta x^{2}}{12}+\frac{k \Delta t}{2}\right] \delta_{x}^{2}\right]\left[1+\left[\frac{\Delta y^{2}}{12}+\frac{k \Delta t}{2}\right] \delta_{y}^{2}\right] } \\
\times & {\left[1+\left[\frac{\Delta z^{2}}{12}+\frac{k \Delta t}{2}\right] \delta_{z}^{2}\right] T_{i j k}^{n}, } \\
& {\left[1+\left[\frac{\Delta y^{2}}{12}-\frac{k \Delta t}{2}\right] \delta_{y}^{2}\right] T_{i j k}^{*}=T_{i j k}^{* *} } \\
& {\left[1+\left[\frac{\Delta z^{2}}{12}-\frac{k \Delta t}{2}\right] \delta_{z}^{2}\right] T_{i j k}^{n+1}=T_{i j k}^{*} }
\end{aligned}
$$

where $k=\left(\lambda / \rho c_{p}^{\prime}\right) ; \delta_{x}^{2}, \delta_{y}^{2}$, and $\delta_{z}^{2}$ are the second-order central difference operators.

Finally, $T_{i j k}^{n+1}$ can be obtained from (6). Each step has a tridiagonal system of equations that can be quickly calculated using the Thomas algorithm [16].

The calculation speed of this high-order mathematical model is faster because it is unconditionally stable. Table 1

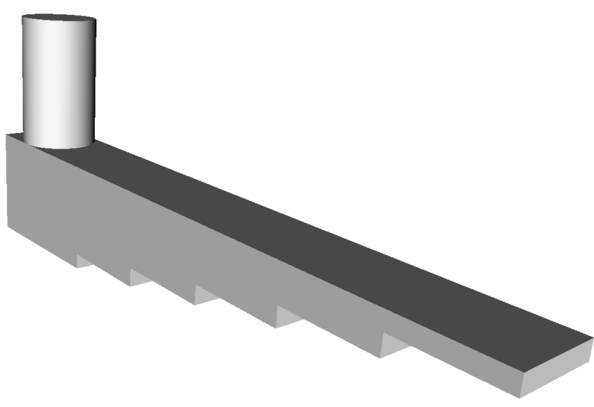

Figure 1: 3D model.

shows that this high-order mathematical model is more accurate than the EFD method.

Because the figure analysis cannot be used for quantitative analysis, the fuzzy mathematical theory is introduced [1519]. The fuzzy set $A$ of the universe of discourse $U, U=$ $\left\{t_{1}, t_{2}, t_{3}, \ldots, t_{n}\right\}$, with a generic element of $U$ denoted by $t_{i}$, is a set of ordered pairs $\left\{\left(t_{1}, A\left(t_{1}\right)\right),\left(t_{2}, A\left(t_{2}\right)\right), \ldots,\left(t_{n}, A\left(t_{n}\right)\right)\right\}$, where $A\left(t_{i}\right)$ is the membership function of the fuzzy set $A, A\left(t_{i}\right): U \rightarrow[0,1]$, and $A\left(t_{i}\right)$ indicates the grade of membership of $t_{i}$ in $A$. Similar expression for the fuzzy set $B$ is readily understood with obvious notation.

In this study, $t_{i}$ represents time nodes; $A\left(t_{i}\right)=\left(T_{A t_{i}} / T_{\infty}\right)$ and $B_{(1 \mathrm{or} 2)}\left(t_{i}\right)=\left(T_{B(1 \mathrm{or} 2) t_{i}} / T_{\infty}\right)$ are two membership functions; $T_{A t_{i}}$ is the experimentally derived temperature; $T_{B(1 \text { or } 2) t_{i}}$ is the temperature obtained by simulation; and $T_{\infty}$ denotes the "typical" temperature [19-21].

According to the $\mathrm{HD}$, the degree of similarity between sets $A$ and $B$ can be evaluated by the function $N(A, B)$ :

$$
N(A, B)=1-\left(\frac{1}{n}\right) \sum_{i=1}^{n}\left|A\left(t_{i}\right)-B\left(t_{i}\right)\right| .
$$

Equation (7) is used to quantitatively analyze the degree of similarity between the simulation results and the experimental results.

\section{Experimental Results and Discussion}

The $3 \mathrm{D}$ model is shown in Figure 1; the geometric figure of the casting is shown in Figure 2; the casting mould is $200 \mathrm{~mm} \times 100 \mathrm{~mm} \times 100 \mathrm{~mm}$; the pouring speed is $0.35 \mathrm{~m} / \mathrm{s}$; and the pouring temperature is $670^{\circ} \mathrm{C}$. The necessary physical parameters are shown in Table 2 . The size of the mesh is $1.0 \mathrm{~mm} \times 1.0 \mathrm{~mm} \times 1.0 \mathrm{~mm}$ and the number of meshes is $2,000,000$.

All of the thermocouples are connected by coaxial cables to a data logger and interfaced with a computer. The temperature data are automatically acquired. A schematic representation of the experimental setup, which is connected 
TABle 2: Physical parameters of casting and mold.

\begin{tabular}{lccccc}
\hline Material & $\begin{array}{c}\text { Latent heat } \\
(\mathrm{kJ} / \mathrm{kg})\end{array}$ & $\begin{array}{c}\text { Density } \\
\left(\mathrm{kg} / \mathrm{m}^{3}\right)\end{array}$ & $\begin{array}{c}\text { Specific heat } \\
(\mathrm{kJ} / \mathrm{kg} \cdot \mathrm{K})\end{array}$ & $\begin{array}{c}\text { Solidus temperature } \\
\left({ }^{\circ} \mathrm{C}\right)\end{array}$ & $\begin{array}{c}\text { Liquidus temperature } \\
\left({ }^{\circ} \mathrm{C}\right)\end{array}$ \\
\hline $\mathrm{AlSi}_{9} \mathrm{Cu}_{3}$ & 471 & $2596-2750$ & $0.83-0.97$ & 504 & 585 \\
Sand & - & 2780 & $0.54-1.00$ & - & - \\
\hline
\end{tabular}

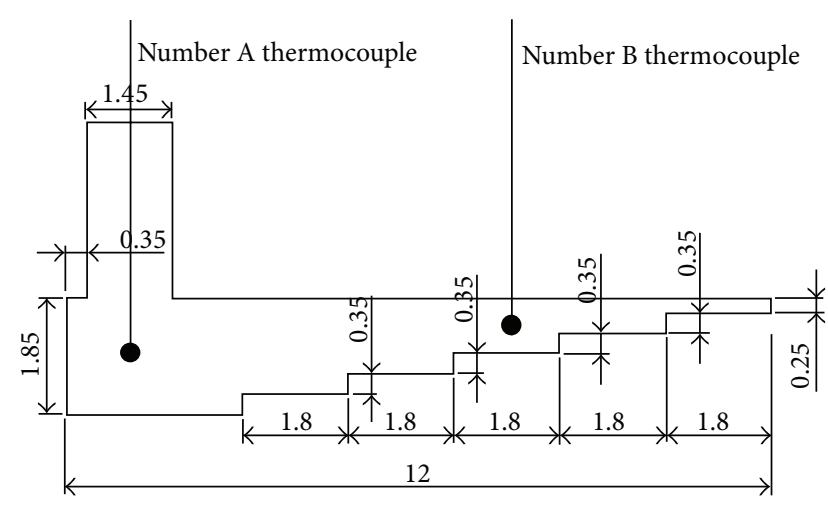

FIGURE 2: Schematic diagram of the experimental setup $(\mathrm{cm})$.

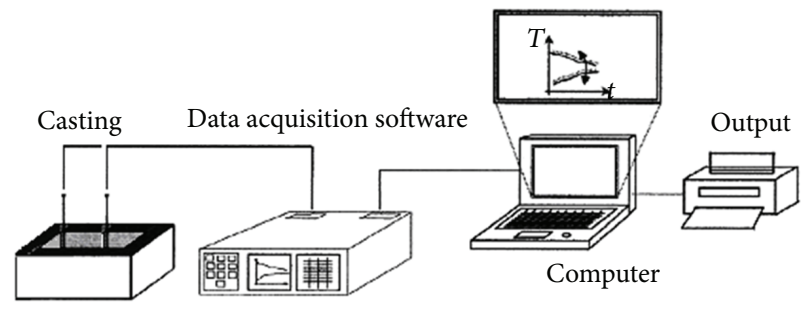

FIGURE 3: Schematic representation of the experimental setup connected to the data acquisition and analysis system.

to the data acquisition and analysis system, is shown in Figure 3. The experimental results are shown in Figure 4.

3.1. Temperature Simulation of Point A. In this section, the high-order mathematical model, which is based on the equivalent specific heat method and the high-order ADI method, is used to compute the energy conservation equation. First, the number of casting meshes is 124031 and this number remains constant. The different time steps $(\Delta t=0.000026 \mathrm{~s}, 20 \Delta t=$ $0.00052 \mathrm{~s}$, and $200 \Delta t=0.0052 \mathrm{~s}$ ) are adopted to compute the temperature simulation of point A. Second, the time step is $20 \Delta t$ and this remains constant. The different mesh numbers $(6825,124031$, and 672963) are adopted to compute the temperature simulation of point $\mathrm{A}$. The hamming distance can be used to evaluate the degrees of similarity between the simulation results and the experimental results. The figure analysis is shown in Figure 5.

Let $U$ be the universe of discourse, $U=\left\{t_{1}=0.0 \mathrm{~s}, t_{2}=\right.$ $\left.0.2 \mathrm{~s}, t_{3}=0.4 \mathrm{~s}, t_{4}=0.6 \mathrm{~s}, \ldots, t_{10}=1.8 \mathrm{~s}\right\}$, with a generic element of $U$ denoted by $t_{i} ; T_{\infty}=671^{\circ} \mathrm{C}$ denotes "typical" temperature; $A\left(t_{i}\right)=\left(T_{A t_{i}} / T_{\infty}\right)$ and $B\left(t_{i}\right)=\left(T_{B t_{i}} / T_{\infty}\right)$ are two membership functions; $T_{A t_{i}}$ represents a temperature measured from the experimental method, and $T_{B t_{i}}$ represents

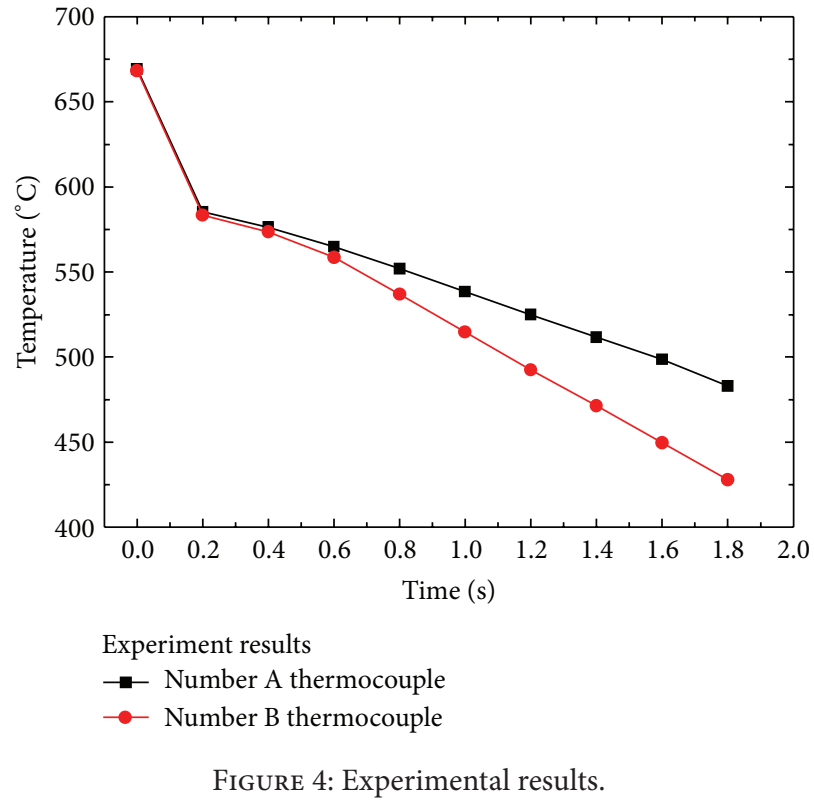

the temperature derived from the simulation method. These include the different time steps and the different mesh numbers.

The fuzzy set $A$ can be described as follows:

$$
\begin{aligned}
A=\{( & \left.t_{1},\left(\frac{669.2}{671}\right)\right),\left(t_{2},\left(\frac{585.4}{671}\right)\right), \\
& \left(t_{3},\left(\frac{576.2}{671}\right)\right),\left(t_{4},\left(\frac{564.8}{671}\right)\right), \\
& \left(t_{5},\left(\frac{551.9}{671}\right)\right),\left(t_{6},\left(\frac{538.4}{671}\right)\right), \\
& \left(t_{7},\left(\frac{525.0}{671}\right)\right),\left(t_{8},\left(\frac{511.6}{671}\right)\right), \\
& \left.\left(t_{9},\left(\frac{498.7}{671}\right)\right),\left(t_{10},\left(\frac{483.0}{671}\right)\right)\right\} .
\end{aligned}
$$

The mesh number remains constant.

(1) The time step is $\Delta t$ and the number of casting meshes is 124031. The fuzzy set $B$ can be described as follows:

$$
\begin{array}{r}
B_{1}=\left\{\left(t_{1},\left(\frac{669.5}{671}\right)\right),\left(t_{2},\left(\frac{585.6}{671}\right)\right),\right. \\
\left(t_{3},\left(\frac{577.0}{671}\right)\right),\left(t_{4},\left(\frac{566.7}{671}\right)\right),
\end{array}
$$




$$
\begin{aligned}
& \left(t_{5},\left(\frac{555.3}{671}\right)\right),\left(t_{6},\left(\frac{539.8}{671}\right)\right), \\
& \left(t_{7},\left(\frac{526.9}{671}\right)\right),\left(t_{8},\left(\frac{512.9}{671}\right)\right), \\
& \left.\left(t_{9},\left(\frac{499.9}{671}\right)\right),\left(t_{10},\left(\frac{485.1}{671}\right)\right)\right\} .
\end{aligned}
$$

According to (7), the degree of similarity between sets $A$ and $B$ can be evaluated:

$$
\begin{aligned}
N\left(A, B_{1}\right) & =1-\left(\frac{1}{10}\right) \sum_{i=1}^{10}\left|A\left(t_{i}\right)-B\left(t_{i}\right)\right| \\
& =0.997839 .
\end{aligned}
$$

(2) The time step is $20 \Delta t$ and the number of casting meshes is 124031 . The fuzzy set $B$ can be described as follows:

$$
\begin{aligned}
B_{2}=\{( & \left.t_{1},\left(\frac{669.8}{671}\right)\right),\left(t_{2},\left(\frac{590.7}{671}\right)\right), \\
& \left(t_{3},\left(\frac{583.3}{671}\right)\right),\left(t_{4},\left(\frac{573.2}{671}\right)\right), \\
& \left(t_{5},\left(\frac{560.8}{671}\right)\right),\left(t_{6},\left(\frac{548.9}{671}\right)\right), \\
& \left(t_{7},\left(\frac{534.7}{671}\right)\right),\left(t_{8},\left(\frac{520.5}{671}\right)\right), \\
& \left.\left(t_{9},\left(\frac{508.1}{671}\right)\right),\left(t_{10},\left(\frac{490.3}{671}\right)\right)\right\} .
\end{aligned}
$$

According to (7), the degree of similarity between sets $A$ and $B$ can be evaluated:

$$
\begin{aligned}
N\left(A, B_{2}\right) & =1-\left(\frac{1}{10}\right) \sum_{i=1}^{10}\left|A\left(t_{i}\right)-B\left(t_{i}\right)\right| \\
& =0.988659 .
\end{aligned}
$$

(3) The time step is $200 \Delta t$ and the number of casting meshes is 124031 . The fuzzy set $B$ can be described as follows:

$$
\begin{aligned}
B_{3}=\{ & \left(t_{1},\left(\frac{669.9}{671}\right)\right),\left(t_{2},\left(\frac{607.8}{671}\right)\right), \\
& \left(t_{3},\left(\frac{599.1}{671}\right)\right),\left(t_{4},\left(\frac{590.5}{671}\right)\right), \\
& \left(t_{5},\left(\frac{580.3}{671}\right)\right),\left(t_{6},\left(\frac{570.2}{671}\right)\right), \\
& \left(t_{7},\left(\frac{556.9}{671}\right)\right),\left(t_{8},\left(\frac{545.3}{671}\right)\right), \\
& \left.\left(t_{9},\left(\frac{533.2}{671}\right)\right),\left(t_{10},\left(\frac{523.0}{671}\right)\right)\right\} .
\end{aligned}
$$

According to (7), the degree of similarity between sets $A$ and $B$ can be evaluated:

$$
\begin{aligned}
N\left(A, B_{3}\right) & =1-\left(\frac{1}{10}\right) \sum_{i=1}^{10}\left|A\left(t_{i}\right)-B\left(t_{i}\right)\right| \\
& =0.959463 .
\end{aligned}
$$

The time step remains constant.

(1) The time step is $20 \Delta t$ and the number of casting meshes is 6825 . The fuzzy set $B$ can be described as follows:

$$
\begin{aligned}
B_{4}=\{ & \left(t_{1},\left(\frac{669.9}{671}\right)\right),\left(t_{2},\left(\frac{592.7}{671}\right)\right), \\
& \left(t_{3},\left(\frac{584.3}{671}\right)\right),\left(t_{4},\left(\frac{575.5}{671}\right)\right), \\
& \left(t_{5},\left(\frac{562.8}{671}\right)\right),\left(t_{6},\left(\frac{549.9}{671}\right)\right), \\
& \left(t_{7},\left(\frac{537.7}{671}\right)\right),\left(t_{8},\left(\frac{521.5}{671}\right)\right), \\
& \left.\left(t_{9},\left(\frac{510.1}{671}\right)\right),\left(t_{10},\left(\frac{492.3}{671}\right)\right)\right\} .
\end{aligned}
$$

According to (7), the degree of similarity between sets $A$ and $B$ can be evaluated:

$$
\begin{aligned}
N\left(A, B_{4}\right) & =1-\left(\frac{1}{10}\right) \sum_{i=1}^{10}\left|A\left(t_{i}\right)-B\left(t_{i}\right)\right| \\
& =0.986140 .
\end{aligned}
$$

(2) The time step is $20 \Delta t$ and the number of casting meshes is 672963 . The fuzzy set $B$ can be described as follows:

$$
\begin{aligned}
B_{5}=\{ & \left(t_{1},\left(\frac{669.1}{671}\right)\right),\left(t_{2},\left(\frac{586.9}{671}\right)\right), \\
& \left(t_{3},\left(\frac{578.9}{671}\right)\right),\left(t_{4},\left(\frac{567.7}{671}\right)\right), \\
& \left(t_{5},\left(\frac{555.7}{671}\right)\right),\left(t_{6},\left(\frac{542.5}{671}\right)\right), \\
& \left(t_{7},\left(\frac{527.9}{671}\right)\right),\left(t_{8},\left(\frac{514.9}{671}\right)\right), \\
& \left.\left(t_{9},\left(\frac{502.1}{671}\right)\right),\left(t_{10},\left(\frac{485.7}{671}\right)\right)\right\} .
\end{aligned}
$$

According to (7), the degree of similarity between sets $A$ and $B$ can be evaluated:

$$
\begin{aligned}
N\left(A, B_{5}\right) & =1-\left(\frac{1}{10}\right) \sum_{i=1}^{10}\left|A\left(t_{i}\right)-B\left(t_{i}\right)\right| \\
& =0.995946 .
\end{aligned}
$$


TABLE 3: The comparison results of calculation time.

\begin{tabular}{lcc}
\hline Method & The number of casting meshes & Calculation time/second \\
\hline The EFD method & 124031 & 2579 \\
This new high-order mathematical model (the time step is $5 \Delta t)$ & 124031 & 1742 \\
This new high-order mathematical model (the time step is $20 \Delta t)$ & 124031 & 253 \\
\hline
\end{tabular}

The hardware environment: microcomputer.

The error of temperature field simulation comes from model simplification, the acceptable hypotheses and calculation errors that can be caused by the different time steps, and the different mesh numbers that are involved in the process of numerical simulation. Because the heat transfer model is based on the energy conservation equation (see (1)) and the governing equations (6), the loss of accuracy comes from calculation error that can be caused by the different time steps and the different mesh numbers.

The conclusions of the analysis and computations can be described as follows.

(1) The number of casting meshes remains constant and the different time steps are adopted to compute the temperature simulation, with great changes in the degrees of similarity between the simulation results and the experimental results:

$$
\begin{aligned}
& \left(N\left(A, B_{1}\right)=0.997839, N\left(A, B_{2}\right)\right. \\
& \left.\quad=0.988659, N\left(A, B_{3}\right)=0.959463\right) .
\end{aligned}
$$

(2) The time step remains constant and the different mesh numbers are adopted to compute the temperature simulation, with the degrees of similarity between the simulation results and the experimental results changing slightly:

$$
\begin{aligned}
& \left(N\left(A, B_{4}\right)=0.986140, N\left(A, B_{2}\right)\right. \\
& \left.\quad=0.988659, N\left(A, B_{5}\right)=0.995946\right) .
\end{aligned}
$$

In short, this high-order mathematical model is based on the equivalent specific heat method and the high-order ADI method, which can be used to calculate the temperature field. For the thick-walled position (see point A), the time step has a large influence on the simulation results of the temperature field and the number of casting meshes has little influence on the simulation results of temperature field.

In Figure 5, for the thick-walled position, the same conclusions hold: (a) the number of casting meshes remains constant and the changes of the time steps change the simulation results of the temperature field; (b) the time step remains constant and change in the mesh numbers brings little change in the simulation results of the temperature field. These are given to illustrate the validity of the analysis method that uses the hamming distance.

The simulation results and the experimental results can only be qualitatively analyzed by the figure analysis. For the first time, this study analyzes the hamming distance to quantitatively ascertain the degree of similarity between the simulation results and the experimental results. The quantitative analysis is based on hamming distance and it is more accurate than qualitative analysis based on the figure analysis.

3.2. Temperature Simulation of Point B. The analysis method is similar and its steps are as follows. First, the number of casting meshes is 124031 and this number remains constant. The different time steps $(\Delta t=0.000026 \mathrm{~s}, 20 \Delta t=0.00052 \mathrm{~s}$, and $200 \Delta t=0.0052 \mathrm{~s}$ ) are adopted to compute the temperature simulation of point B. Second, the time step is $20 \Delta t$ and this remains constant. The different mesh numbers (6825, 124031, and 672963) are adopted to compute the temperature simulation of point $\mathrm{B}$. The hamming distance can evaluate the degrees of similarity between the simulation results and the experimental results. Figure 6 illustrates the validity of the analysis method of the hamming distance.

The conclusions are that for the thin-walled position (see point B); the time step has little influence on the simulation results of the temperature field and the number of casting meshes has a large influence on the simulation results of the temperature field.

This high-order mathematical model, which is based on the equivalent specific heat method and the high-order ADI method, is superior to the explicit finite difference method. In this section, the number of casting meshes remains constant and the calculation time between the explicit finite difference method and the high-order mathematical model is shown in Table 3.

\section{Conclusions}

(1) The high-order mathematical model based on the equivalent specific heat method and the high-order ADI method can be used to effectively compute the temperature simulation. Because this mathematical model is unconditionally stable, the different time steps can be chosen with quick calculation.

(2) For the first time, this paper demonstrates how the analysis method of the hamming distance can be used to quantitatively analyze the degree of similarity between the simulation results of the temperature field and the experimental results of the temperature field.

(3) For the thick-walled position (see point A), the time step has a large influence on the simulation results of the temperature field and the number of casting meshes has little influence on the simulation results of the temperature field. For the thin-walled position 

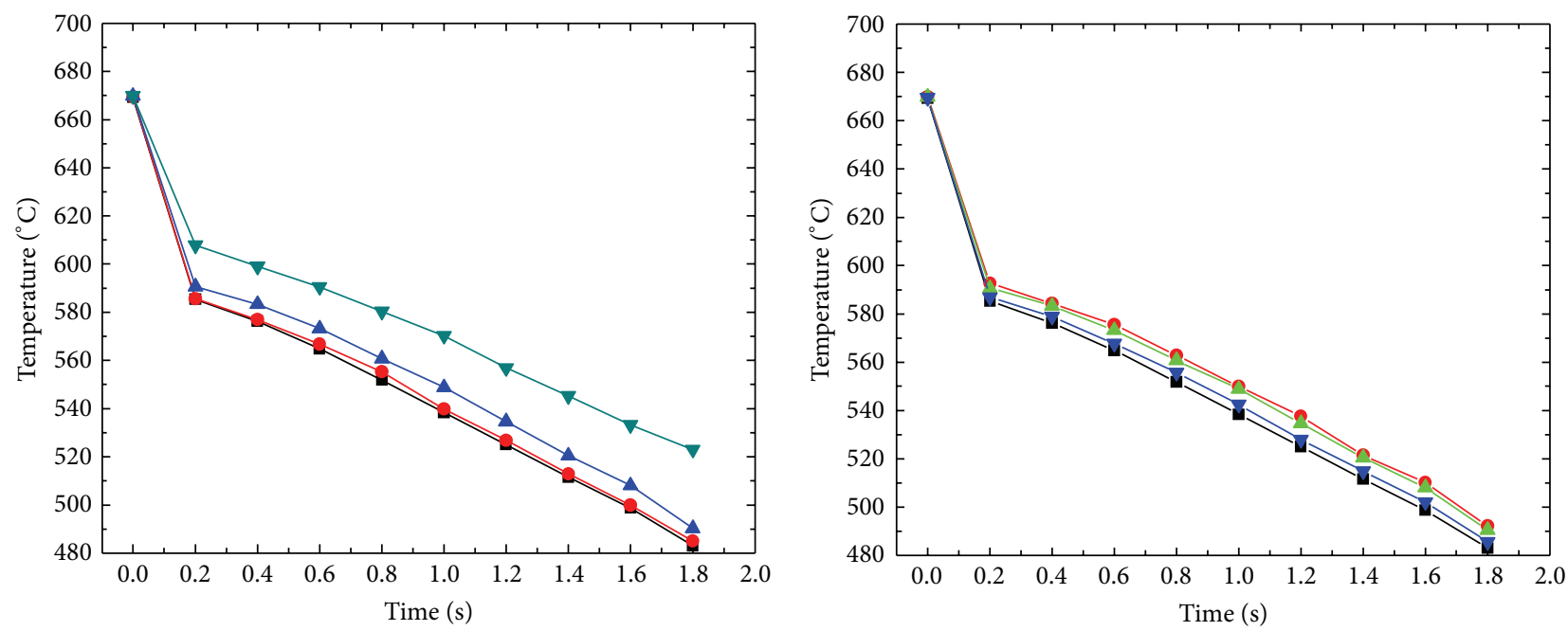

Number A thermocouple

Number A thermocouple

- Experiment results

-ø- Experiment results

- - The number of casting meshes is 6825

- The time step is $0.00026 \mathrm{~s}$

- - The number of casting meshes is 124031

$\rightarrow$ The time step is $0.0052 \mathrm{~s}$

The number of casting meshes is 124031 .

(a) The mesh number remains constant

$-\nabla$ - The number of casting meshes is 672963

The time step is $0.00052 \mathrm{~s}$.

(b) The time step remains constant

FIGURE 5: Comparison results.

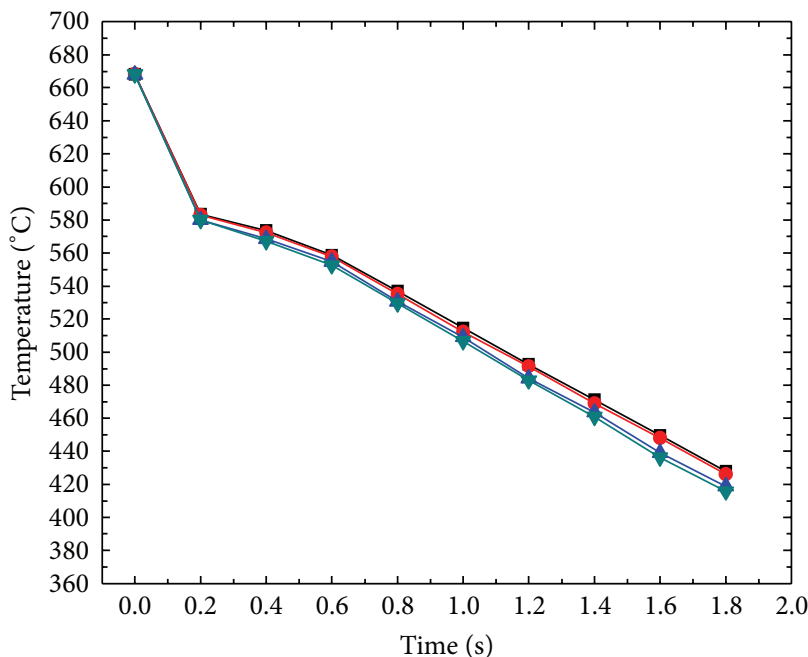

Number B thermocouple

- Experiment results

- The time step is $0.00026 \mathrm{~s}$

—- The time step is $0.00052 \mathrm{~s}$

$\rightarrow-$ The time step is $0.0052 \mathrm{~s}$

The number of casting meshes is 124031 .

(a) The mesh number remains constant

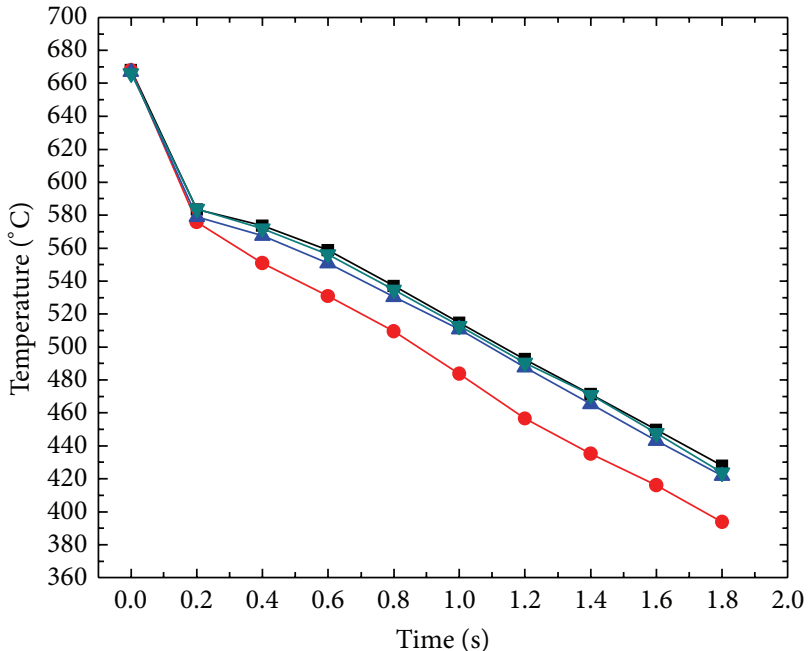

Number B thermocouple

$\rightarrow$ Experiment results

- The number of casting meshes is 6825

_- The number of casting meshes is 124031

$\rightarrow$ The number of casting meshes is 672963

The time step is $0.00052 \mathrm{~s}$.

(b) The time step remains constant

Figure 6: Comparison results. 
(see point B), the time step has little influence on the simulation results of the temperature field and the number of casting meshes has a sizable influence on the simulation results of the temperature field.

\section{Acknowledgment}

This research is financially supported by the National Natural Science Foundation of China (Grant nos. 51304145 and 51301118).

\section{References}

[1] D.-C. Tsai and W.-S. Hwang, "Numerical simulation of solidification morphologies of $\mathrm{Cu}-0.6 \mathrm{Cr}$ casting alloy using modified cellular automaton model," Transactions of Nonferrous Metals Society of China, vol. 20, no. 6, pp. 1072-1077, 2010.

[2] Y. Chen, Y.-H. Zhao, and H. Hou, "Numerical simulation for thermal flow filling process casting," Transactions of Nonferrous Metals Society of China, vol. 16, pp. 214-218, 2010.

[3] X.-F. Niu, W. Liang, Y.-H. Zhao et al., "New algorithm for solving $3 \mathrm{D}$ incompressible viscous equations based on projection method," Transactions of Nonferrous Metals Society of China, vol. 21, no. 8, pp. 1826-1832, 2011.

[4] T. R. Vijayaram, S. Sulaiman, A. M. S. Hamouda, and M. H. M. Ahmad, "Numerical simulation of casting solidification in permanent metallic molds," Journal of Materials Processing Technology, vol. 178, no. 1-3, pp. 29-33, 2006.

[5] X. Niu, W. Liang, Y. Zhao, and H. Hou, "A new implicit finite difference algorithm of thermal melt flow in filling process based on projection method," Journal of Computational and Theoretical Nanoscience, vol. 9, pp. 1-5, 2012.

[6] J.-J. Droux, "Three-dimensional numerical simulation of solidification by an improved explicit scheme," Computer Methods in Applied Mechanics and Engineering, vol. 85, no. 1, pp. 57-74, 1991.

[7] Y.-F. Chiu, Y.-L. Tsai, and W.-S. Hwang, "Mathematical modeling for the solidification heat-transfer phenomena during the reflow process of lead-tin alloy solder joint in electronics packaging," Applied Mathematical Modelling, vol. 27, no. 7, pp. 565-579, 2003.

[8] H. Hou, Studies on Numerical Simulation for Liquid-Metal Filling and Solidification during Casting Process, Saitama Institute of Technology, Saitama, Japan, 2005.

[9] X. P. Zhang, S. M. Xiong, and Q. Y. Xu, "Numerical methods to improve the computational efficiency of solidification simulation for the investment casting process," Journal of Materials Processing Technology, vol. 173, no. 1, pp. 70-74, 2006.

[10] W. Y. Liao, "A high-order ADI finite difference scheme for a $3 \mathrm{D}$ reaction-diffusion equation with neumann boundary condition," Numerical Methods for Partial Differential Equations, vol. 29, no. 3, pp. 778-798, 2013.

[11] S. Karaa and J. Zhang, "High order ADI method for solving unsteady convection-diffusion problems," Journal of Computational Physics, vol. 198, no. 1, pp. 1-9, 2004.

[12] Y.-B. Ge, Z.-F. Tian, and W.-Q. Wu, "A high-order alternating direction implicit method for solving the high dimensional heat equations," Journal of University of Shanghai for Science and Technology, vol. 29, no. 1, pp. 55-58, 2007.

[13] L. A. Zadeh, "Fuzzy sets," Information and Control, vol. 8, no. 3, pp. 338-353, 1965.
[14] R. Scozzafava and B. Vantaggi, "Fuzzy inclusion and similarity through coherent conditional probability," Fuzzy Sets and Systems, vol. 160, no. 3, pp. 292-305, 2009.

[15] C.-Y. Zhang and H.-Y. Fu, "Similarity measures on three kinds of fuzzy sets," Pattern Recognition Letters, vol. 27, no. 12, pp. 1307-1317, 2006.

[16] F.-P. Tan, "A modified Thomas algorithm and its error estimation," in Proceedings of the 14th Conference of International Linear Algebra Society, pp. 261-264, 2007.

[17] Y. Li, D. L. Olson, and Z. Qin, "Similarity measures between intuitionistic fuzzy (vague) sets: a comparative analysis," Pattern Recognition Letters, vol. 28, no. 2, pp. 278-285, 2007.

[18] S. Raha, A. Hossain, and S. Ghosh, "Similarity based approximate reasoning: fuzzy control," Journal of Applied Logic, vol. 6, no. 1, pp. 47-71, 2008.

[19] S.-H. Wei and S.-M. Chen, "A new approach for fuzzy risk analysis based on similarity measures of generalized fuzzy numbers," Expert Systems with Applications, vol. 36, no. 1, pp. 589-598, 2009.

[20] Z. Xu, S. Shang, W. Qian, and W. Shu, "A method for fuzzy risk analysis based on the new similarity of trapezoidal fuzzy numbers," Expert Systems with Applications, vol. 37, no. 3, pp. 1920-1927, 2010.

[21] J. Z. C. Lai, E. Y. T. Juan, and F. J. C. Lai, "Rough clustering using generalized fuzzy clustering algorithm," Pattern Recognition, vol. 46, no. 9, pp. 2538-2547, 2013. 


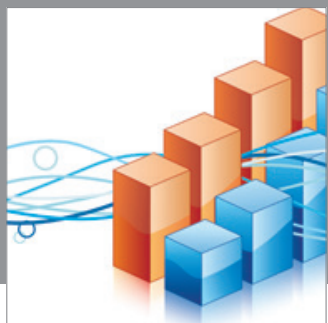

Advances in

Operations Research

mansans

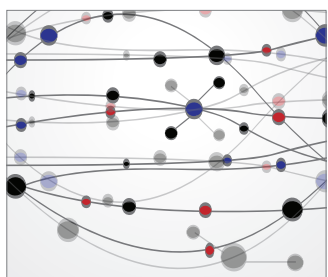

The Scientific World Journal
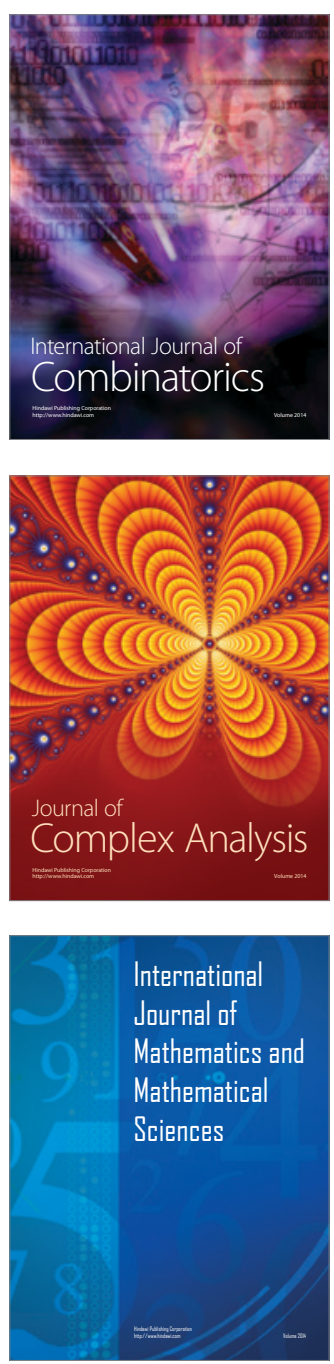
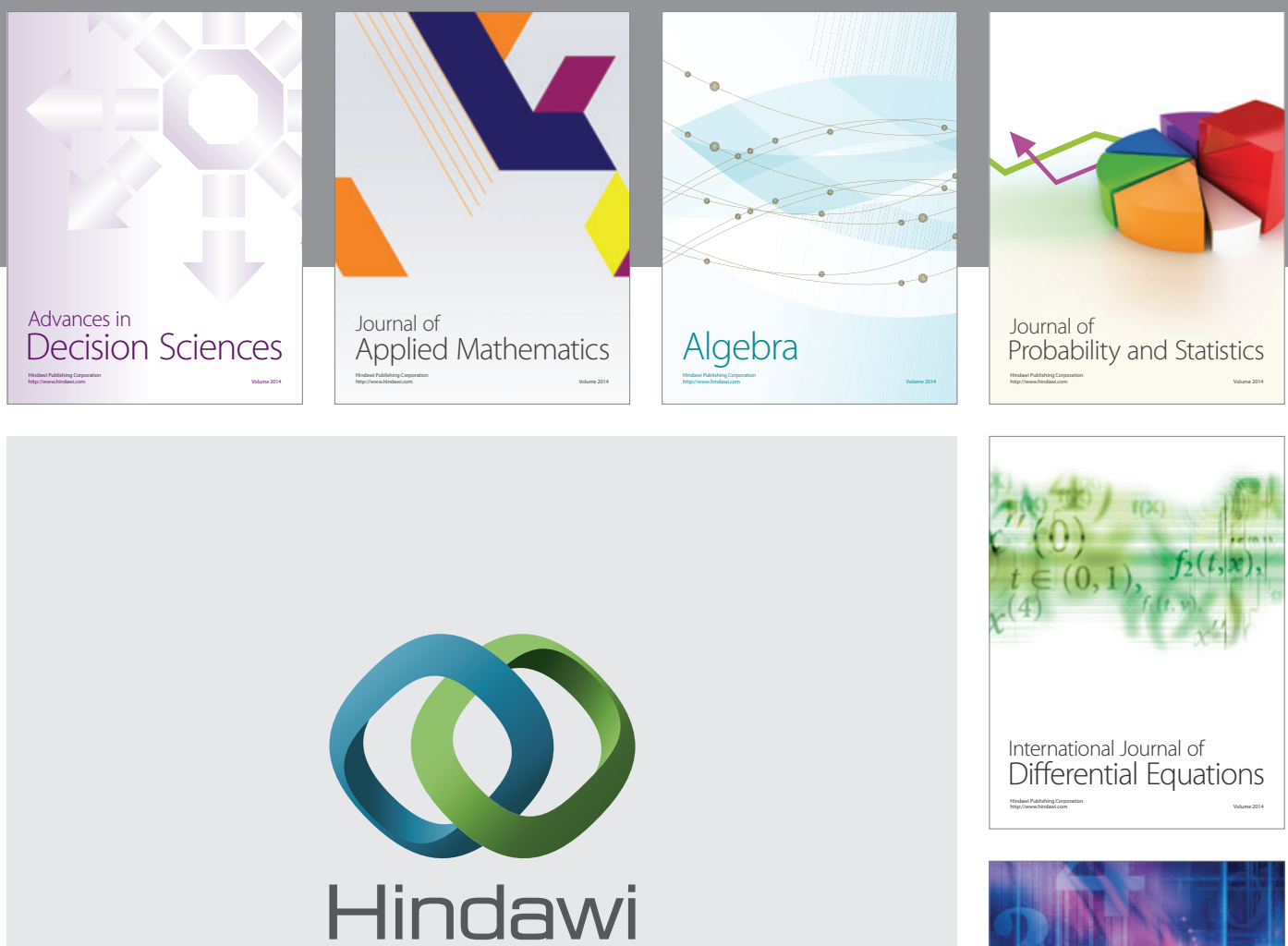

Submit your manuscripts at http://www.hindawi.com
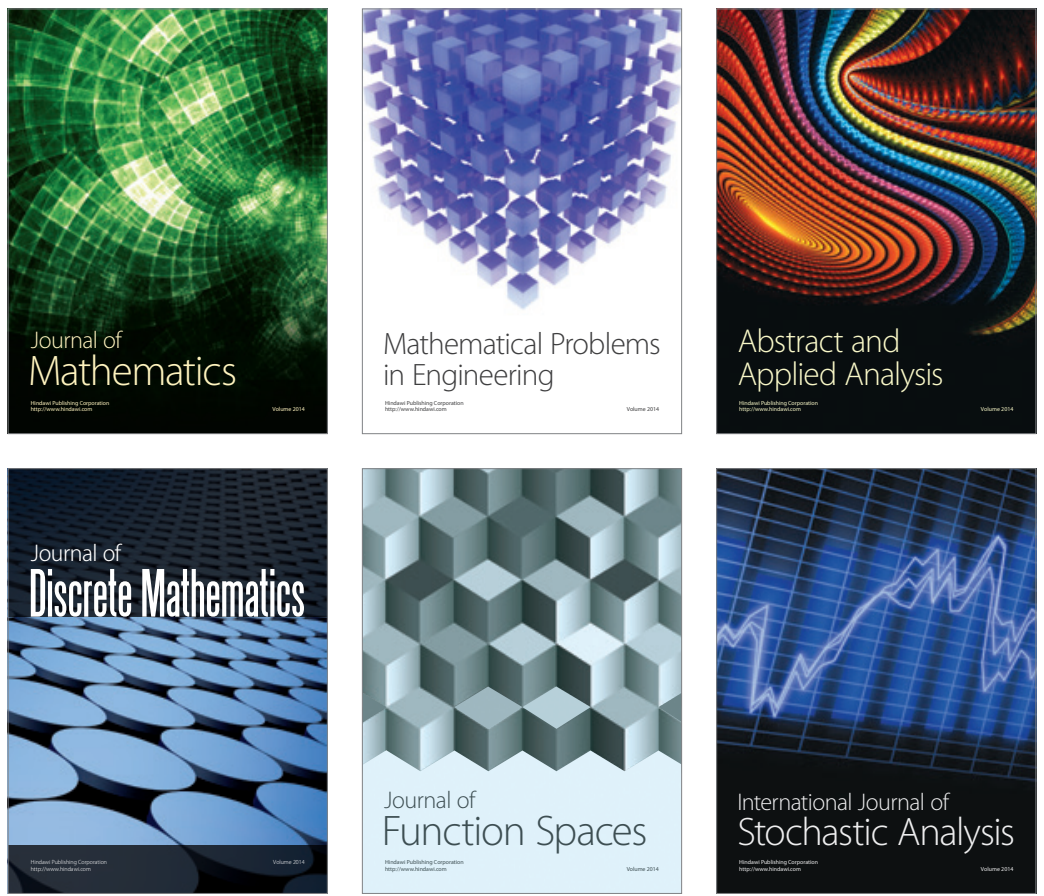

Journal of

Function Spaces

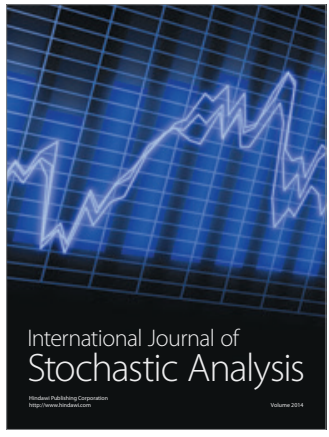

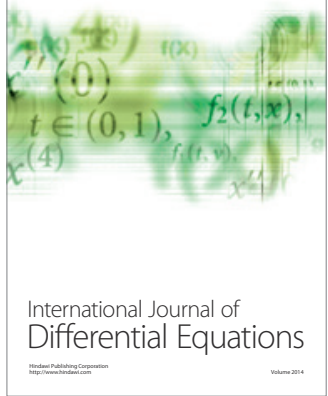
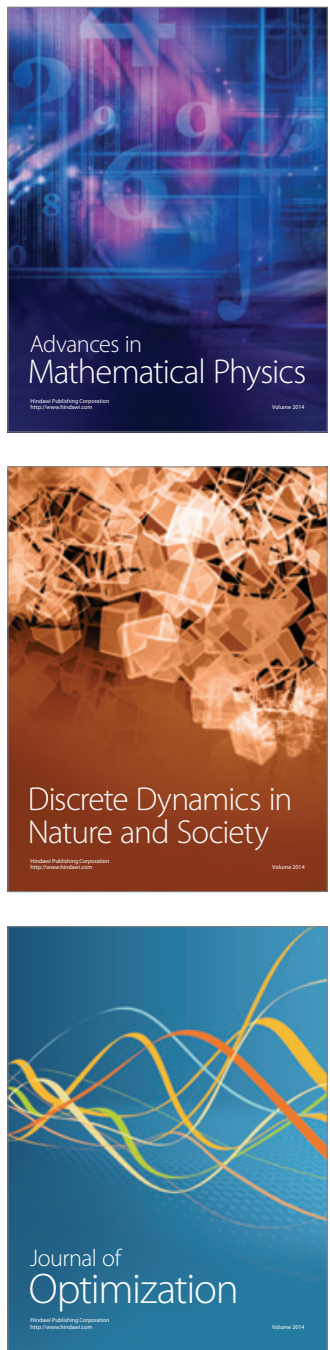